\title{
Empirical Research on Network Size and Technological Progress
}

\author{
Yabin Zhang ${ }^{1}$, Qiang Chen ${ }^{1 *}$ and Tianli Xiong ${ }^{1}$ \\ ${ }^{1}$ School of Economics \& Trade, Hunan University, \\ Changsha, 410079, China
}

\begin{abstract}
The aim of this paper is to examine the correlation between network size and technological progress in China. This study mainly focuses on three aspects. First, we use a data envelopment analysis (DEA) model to calculate the efficiency of technological progress. The result shows that Beijing, Heilongjiang, Shanghai, Jiangsu and Zhejiang, Fujian, Shandong, Hubei, Hunan and Guangdong are at the low level. Tianjin, Hebei, Shanxi, Henan, Guangxi, Hainan, Chongqing, Sichuan, Guizhou, Yunnan and Xinjiang are at the medium level. Shanxi, Liaoning, Jilin, Anhui, Jiangxi, Xizang, Shaanxi, Gansu, Qinghai and Ningxia are at the high level. Second, we use an ordinary least square (OLS) model, an econometric model, to estimate the relationship between the efficiency of technological progress and network size. The result shows that the efficiency of technological progress and network size are significantly related. Finally, we use Structural Holes, a complex network approach, to analyze the correlation of network size in various regions.
\end{abstract}

Keyword: Efficiency of technological progress, Network Size, DEA model, OLS model, Structural Holes

\section{Introduction}

China has become one of the biggest countries in terms of network size in the world. As technological progress is the power source of long-term economic growth, the correlation between network size and technological progress is a worthy research topic. Technological progress has two definitions: technological progress both in the narrow sense and in the broad sense. Technological progress in the narrow sense means technological innovation, whereas in the broad sense it means management innovation or institutional innovation and so on. Biswas (2004) proposed that informatization through production technology and consumption structure can impact economic growth. Frishammar (2005) and Bi (2012) proposed that informatization and process innovation are positively correlated. Shi (2011) and Fang (2013) further proved that informatization and process innovation are positively correlated. There is much literature regarding researching information and technological progress in the narrow sense, but little can be found on information and technological progress in the broad sense. Due to this, this paper investigates the relationship between network size and technological progress in the broad sense in China. First, based on the literature cited above, it is assumed that network size can promote technological progress in a broad sense. Then, empirical research was conducted to test this hypothesis. Second, the paper uses Structural Holes, a complex network approach, to locate the network center of 31 regions in China.

The paper is structured as follows: Section 1 is the introduction. In Section 2 the paper introduces the research method: the DEA-SBM model, the OLS model and Structural Holes. Section 3 demonstrates the results of the DEA-SBM model, the OLS model, and Structural Holes. The conclusion of the paper is presented in Section 4.

* Corresponding Author. 


\section{Method}

In this section, the research method is introduced, including the DEA-SBM model, the OLS model, and Structural Holes.

\subsection{DEA Model}

Charnes, Cooper and Rhodes (1978) proposed Data Envelopment Analysis (DEA). The DEA-SBM model is a non-radial and non-angular DEA model, which can settle the slack problem of input and output. The DEA-SBM (Tone \& Kaoru, 2001) model was selected to calculate the efficiency of technological progress. The formula is as follow:

$$
\begin{gathered}
\min \rho=\frac{\frac{1}{\mathrm{~m}} \sum_{\mathrm{i}=1}^{\mathrm{m}} \mathrm{S}_{\mathrm{i}}^{-} / \mathrm{x}_{\mathrm{ik}}}{1+\frac{1}{\mathrm{q}} \sum_{\mathrm{r}=1}^{\mathrm{q}} \mathrm{S}_{\mathrm{r}}^{+} / \mathrm{y}_{\mathrm{rk}}} \\
\text { s.t.X } \lambda+\mathrm{S}^{-}=\mathrm{X}_{\mathrm{k}} \\
\mathrm{Y} \lambda+\mathrm{S}^{+}=\mathrm{Y}_{\mathrm{k}} \\
\lambda, \mathrm{S}^{-}, \mathrm{S}^{+} \geq 0
\end{gathered}
$$

Here, $\rho$ represents the efficiency. y represents the output of Decision Making Unit (DMU). $\mathrm{x}$ represents the input of DMU. $\mathrm{s}^{+}$and $\mathrm{s}^{-}$represent the slack variable. $\lambda$ represents the weight of DMU.

\subsection{OLS Model}

Ordinary least square (OLS), an econometrics models (Wooldridge, 2006), was adopted to analyze the relationship between technological progress and network size.

$$
\mathrm{Y}_{\mathrm{i}, \mathrm{t}}=\alpha+\sum_{\mathrm{i}=1}^{\mathrm{n}} \beta_{i} X_{i, t}^{n}+\varepsilon_{\mathrm{i}, \mathrm{t}}
$$

Here, $\mathrm{Y}$ represents the efficiency. $\alpha$ represents the intercept. $\beta$ represents the slope. $X$ represents the variable. $\varepsilon$ represents the disturbance.

\subsection{Structural Holes}

Complex network approaches have been receiving more and more attention in recent years. Structural holes analysis is a complex network approach which can analyze the relationship among individuals in order to find the key nodes of network. Structural holes, which originates from social networks, was coined by Burt (1992), who defined a structural hole as "a relationship of non-redundancy between two or more contacts. More and more scholars have begun to use structural holes (Wang, 2013; Guo, 2014 and Chen, 2015). This paper calculates the efficiency of structural holes, and then finds the network center. The formula is as follows: 


$$
\begin{aligned}
& \rho=\frac{\sum_{j}\left(1-\sum_{q} p_{i q} m_{j q}\right)}{C_{i}} \\
& q i, j
\end{aligned}
$$

Here, j represents all the points which are connected with i. q represents all the points of the third party. $p_{i q}$ represents the proportion of $j$ inputs to $q \cdot m_{j q}$ represents marginal strength between $\mathrm{j}$ and q. $\mathrm{C}_{\mathrm{i}}$ represents all the points.

The above formula introduces the structural holes. Then it is necessary to build the network of 31 provinces. The calculation formula of the network is as below:

$$
I_{i, t}=\frac{N_{i, t}+P_{i, t}}{L_{i}}
$$

Here, I represents the network indicator. N represents the network size of users between two provinces. Prepresents the network size of ports between two provinces. $\mathrm{L}$ represents the distance between two provinces.

\subsection{Data Description}

When calculating the efficiency of technological progress, it is conventional to consider two main aspects: the capital factor and the labor factor. Based on these, two input factors and one output factor were selected for calculating. The two input factors include: total investment in fixed assets in the whole country and the number of employed persons in urban units. The one output factor includes GDP. Due to the absence of relevant data in some regions, this paper examines 31 provinces from mainland China (excluding Taiwan, Hong Kong and Macao). This data is sourced from the National Bureau of Statistics of China from 2009 to 2014. Network size (NET): this refers to the average growth rate of the number of internet users and the growth rate of the number of broad band ports. R\&D Level (R\&D): this refers to the ratio of the number of researchers to the number of employees. Industrial Structure (IND): this refers to the ratio of the added value of the secondary industry and GDP. Opening Level (OPE): this refers to the number of foreign funded enterprises. Infrastructure Level (INF): this refers to the Length of Paved Roads. Due to the absence of relevant data, this paper examines 31 provinces from mainland China (excluding Taiwan, Hong Kong and Macao). This data is sourced from the National Bureau of Statistics of China from 2009 to 2014. Network size of users: this refers to the number of internet users in 2014. Network size of ports: this refers to the number of broad band ports in 2014. Distance: this refers to the road distance between two provinces. As the data in some regions is insufficient, the data is sourced from 31 provinces from mainland China (excluding Taiwan, Hong Kong and Macao). The data of the spatial weight matrix is sourced from the Transport Statistical Yearbook of China and the National Bureau of Statistics of China from 2009 to 2014.

\section{Results and Discussion}

In this section, the experiment results and analysis are shown. The results include the efficiency of technological progress, the relationship between network size and technological progress, and the structural holes analysis. 


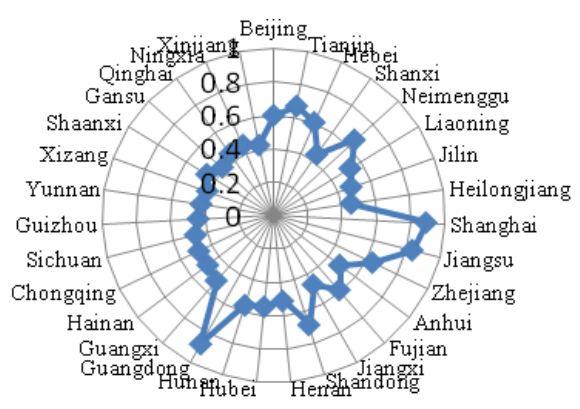

$\longrightarrow 2009$

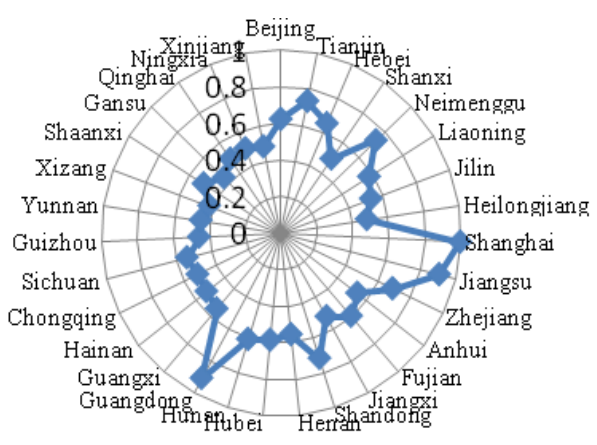

$\longrightarrow 2010$

Figure 1. The Efficiency of Technological Progress in Various Provinces (2009-2010)

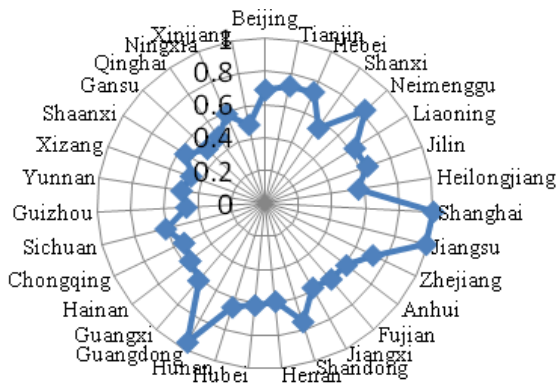

$\multimap 2011$

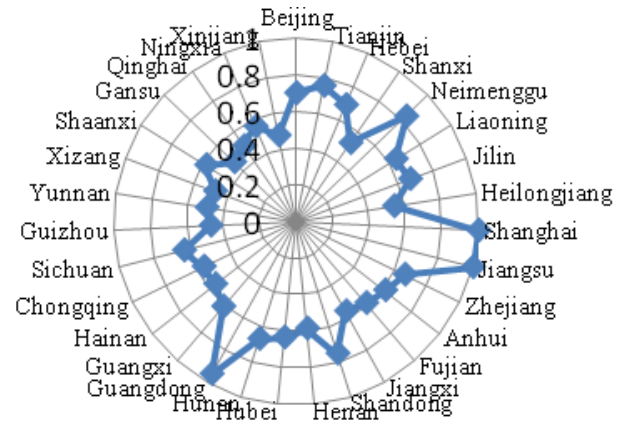

$\leadsto 2012$

Figure 2. The Efficiency of Technological Progress In Various Provinces (2011-2012) 


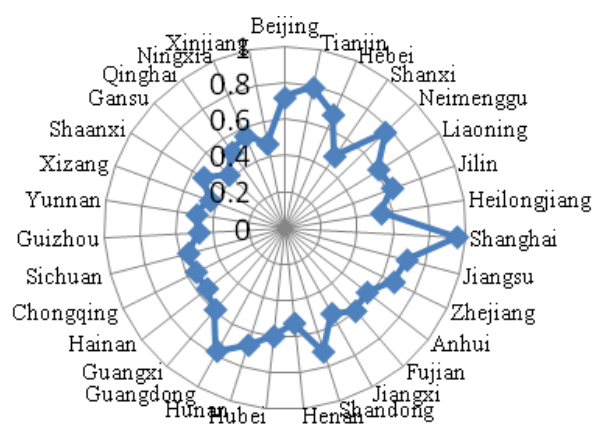

$\multimap 2013$

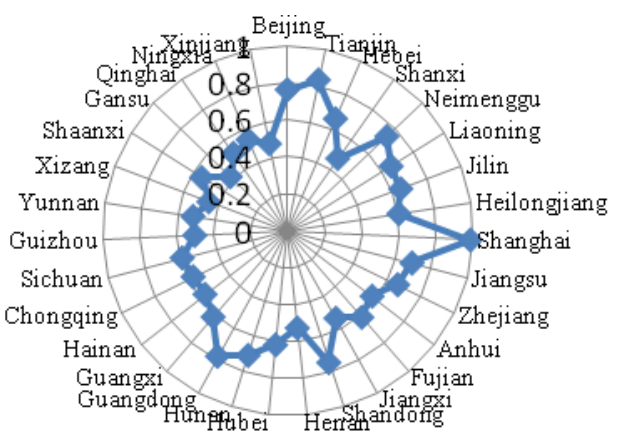

$-2014$

Figure 3. The Efficiency of Technological Progress in Various Provinces (2013-2014)

Figure 1-3 show the efficiency of technological progress of 31 provinces from 2009 to 2014 in China. It can be seen that Shanghai, Guangdong, Jiangsu, Neimenggu, Tianjin, Shandong, Beijing, Zhejiang, Hebei and Hunan are among the top 10 provinces with the highest level from 2009 to 2014. Particularly, we can see that most of these provinces are from the eastern region of China. The reason for this is that the economic level of the eastern region is higher than that of other regions. Therefore, the eastern region has more research funds to improve the efficiency of technological progress. We can see that Jilin, Heilongjiang, Beijing, Tianjin, Liaoning, Hunan, Sichuan, Yunnan, Guangxi and Anhui round out the top 10 regarding growth rate from 2009 to 2014 in China. Most of these provinces are from the central region and western region in China. The reason is that although the economic levels of the central region and western region are relatively lower than that of eastern region, the rate of economic growth is higher than that of eastern region. Figure 4 illustrates the efficiency of technological progress of four regions from 2009 to 2014 in China. As can be seen from the figure, the efficiency of technological progress in the eastern region is significantly higher than that of other regions in China. The main reason given for this is again that the economic level of the eastern region is higher than that of the northeast, central, and western regions. 


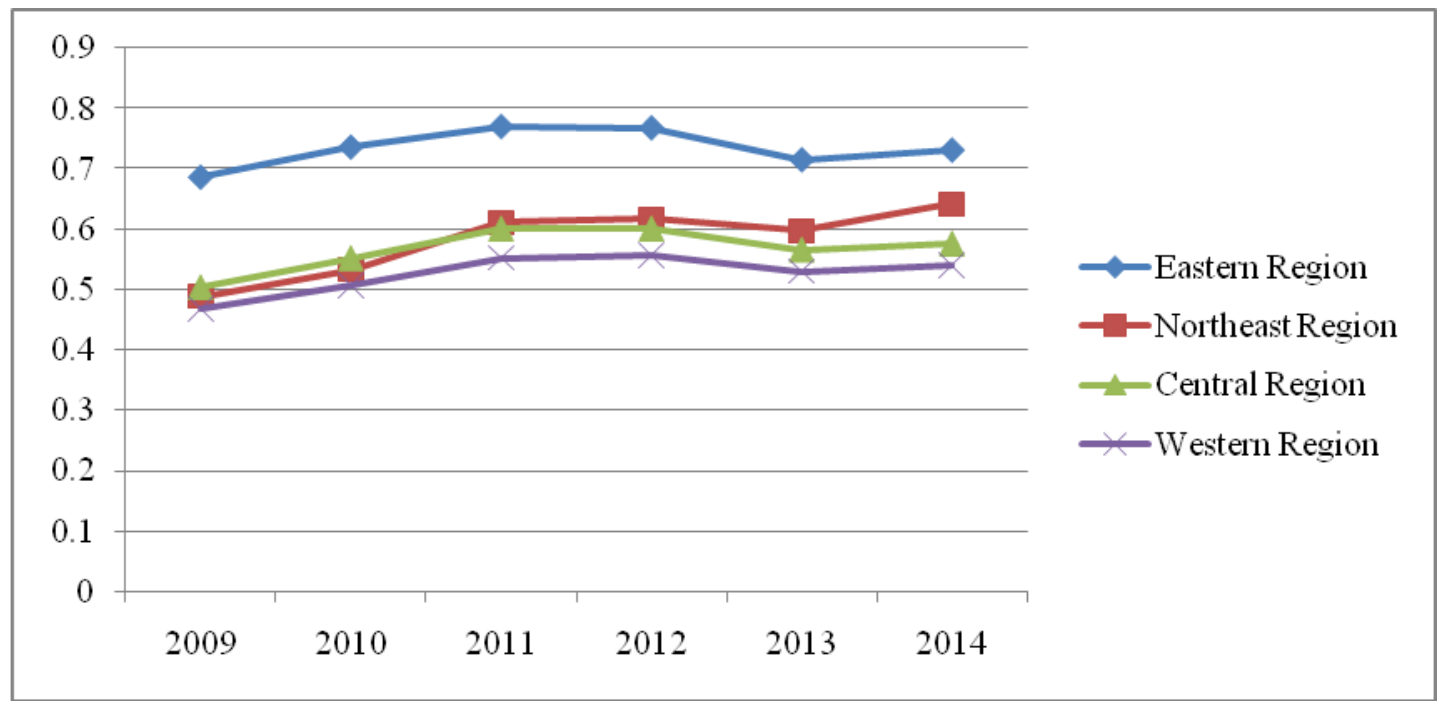

Figure 4. The Efficiency of Technological Progress from Each Region

Table 1 describes the results of the econometric analysis. The results show that network size can significantly and positively impact the efficiency of technological progress. The result proves the hypothesis that network size can impact the technological progress in a broad sense. Moreover, the result also shows that R\&D, IND and OPE can positively impact technological progress. As industrial development cannot do without technological innovation, IND can positively impact the efficiency of technological progress. In addition, OPE can also positively impact technological progress. The reason is that many foreign enterprises, which are from developed countries where the technology level higher than that of developing countries, bring advanced technology to the region where they are investing. Hence, regions with many foreign enterprises need no more advanced technology, and therefore why OPE can promote technological progress.

Table 1. The Regression Result of OLS Model

\begin{tabular}{|l|l|l|}
\hline Variable & OLS & OLS-FE \\
\hline NET & $0.01919^{* * *}$ & $0.02070^{* * *}$ \\
& $(0.00527)$ & $(0.00540)$ \\
\hline R\&D & $11.47751^{* * *}$ & $12.86522^{* * *}$ \\
& $(2.94411)$ & $(3.60067)$ \\
\hline IND & $0.3415348^{*}$ & $0.68806^{* * *}$ \\
& $(0.18323)$ & $(0.24576)$ \\
\hline OPE & 0.2114777 & 0.17693 \\
& $(0.17414)$ & $(0.00111)$ \\
\hline Constant & $0.27223^{* * *}$ & 0.09665 \\
& $(0.08751)$ & $(0.15399)$ \\
\hline Observation & 186 & 186 \\
\hline R - Square & 0.58370 & 0.47990 \\
\hline \multicolumn{1}{|c|}{ Notes: ******and * represent $1 \%$ significance level, 5\% significance level and $10 \%$ significance level respectively. Standard }
\end{tabular}
error is given in parentheses. FE represents the fixed-effect model. 
3.3. The Results of the Structural Holes Analysis

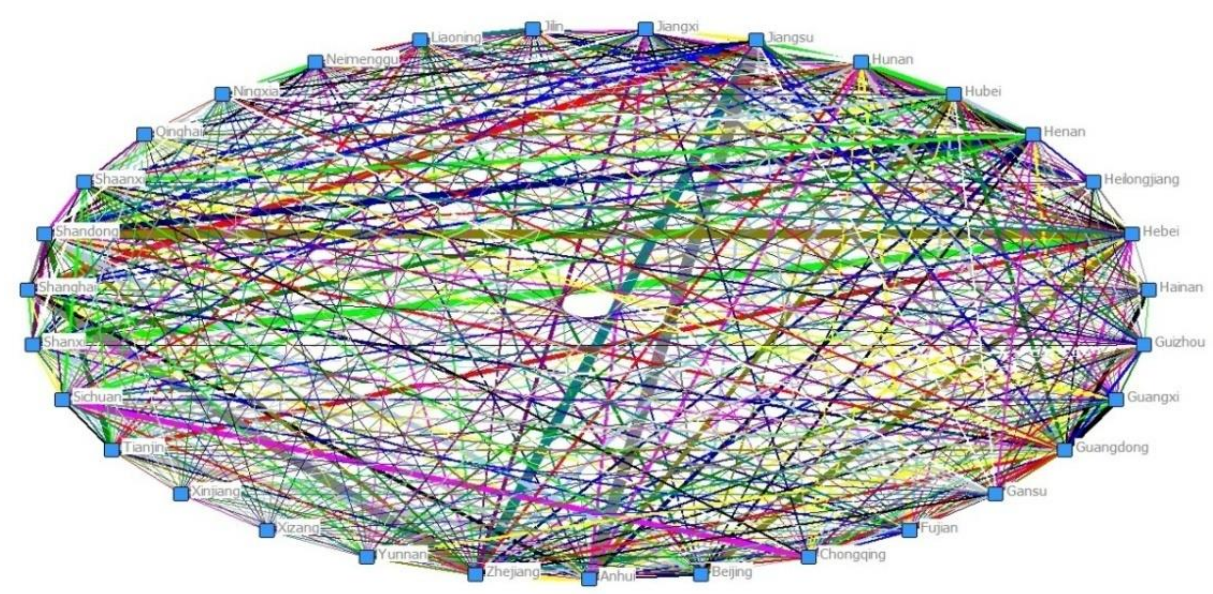

Notes: The line weight means the degree of correlation.

Figure 5. The Network Diagram of 31 Provinces

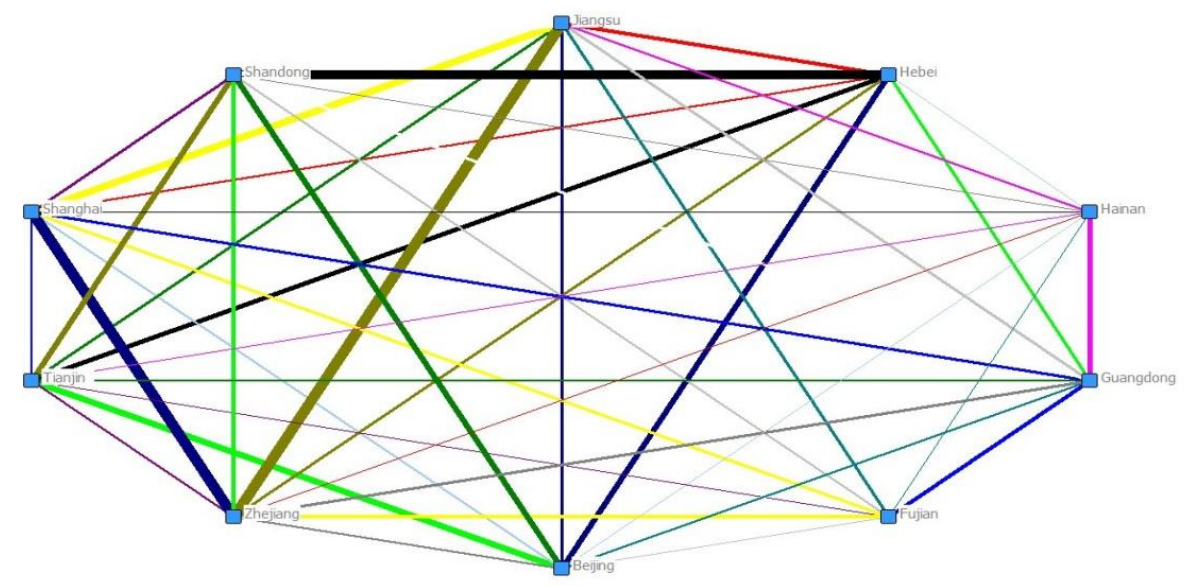

Notes: The line weight means the degree of correlation.

Figure 6. The Network Diagram of the Eastern Region

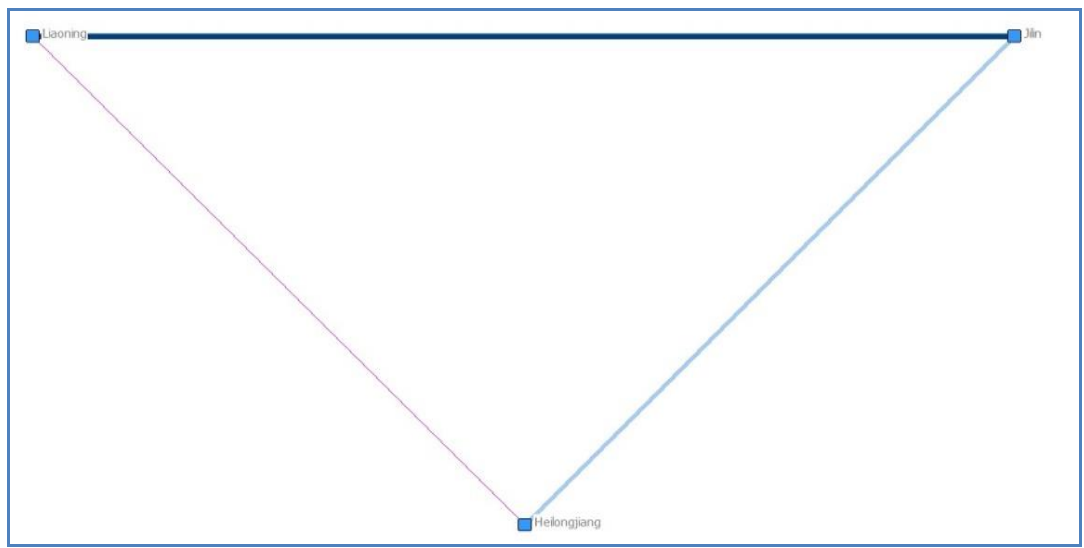

Notes: The line weight means the degree of correlation.

Figure 7. The Network Diagram of the Northeastern Region 


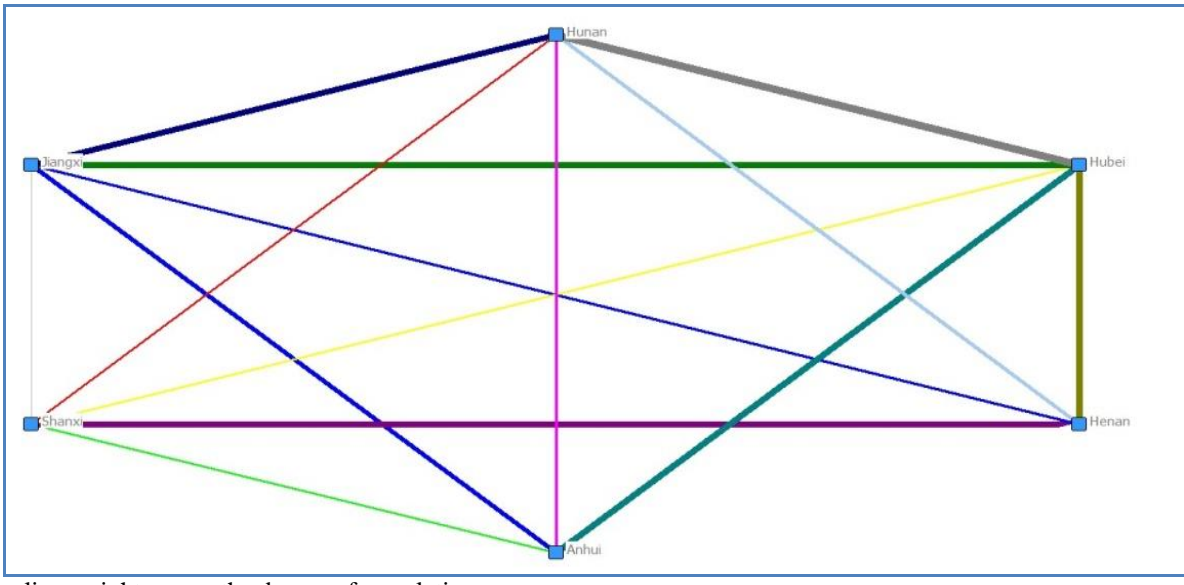

Notes: The line weight means the degree of correlation.

Figure 8. The Network Diagram of the Central Region

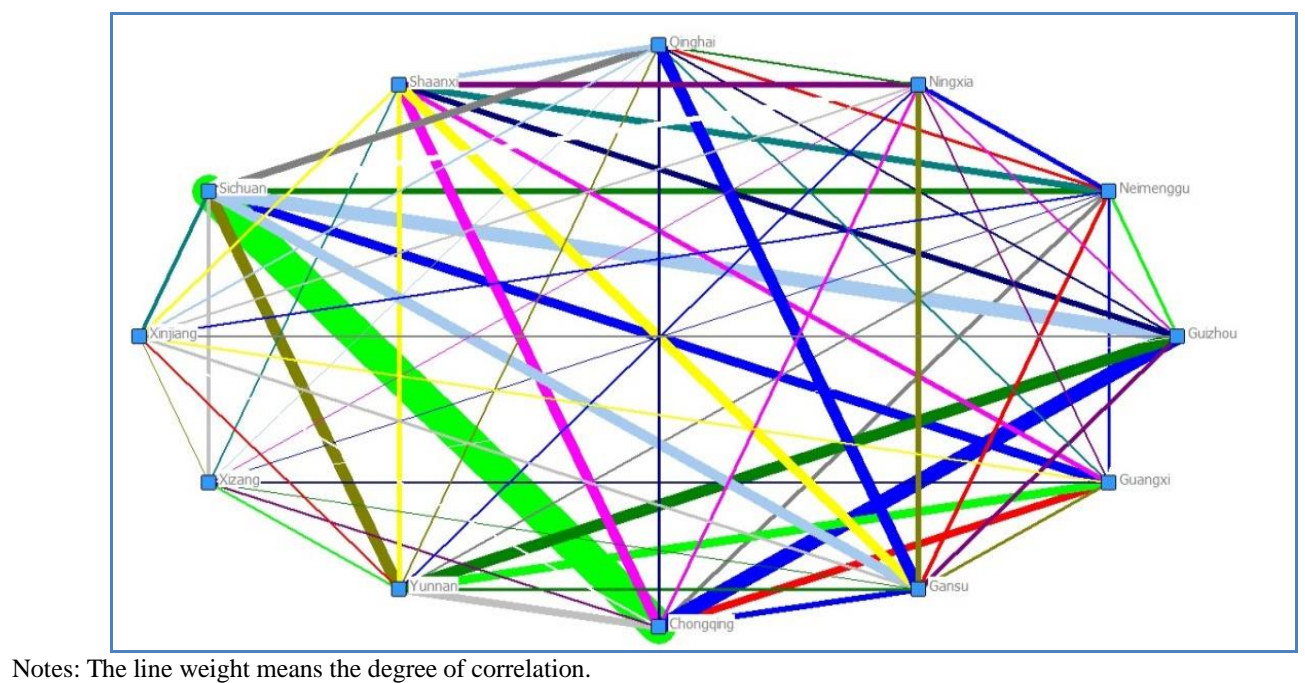

Figure 9. The Network Diagram of the Western Region

Figure 5 visually shows the network relationship between 31 provinces. Figure 6-9 show the network relationship of each region. We can see that each province has contact with each other. Table 2 describes the efficiency of structural holes. First, we can see from Table 2 that the top 10 highest in efficiency are Guangdong, Sichuan, Liaoning, Jilin, Heilongjiang, Gansu, Xinjiang, Guizhou and Yunnan. Particularly, most provinces are from the northeastern region and western region. Moreover, according to the efficiency, the paper locates the center province of each region. The center provinces of the eastern regions are Guangdong, Jiangsu and Hebei. As the efficiency of each province is very close, there are not clear central provinces for the northeastern region. The center province of the central region is Hunan. The center provinces of the western regions are Sichuan, Gansu, Xinjiang, Guizhou and Yunnan. 
Table 2. The Efficiency of Structural Holes

\begin{tabular}{|l|l|l|l|}
\hline Province & Efficiency & Province & Efficiency \\
\hline Beijing & 0.657 & Hubei & 0.658 \\
\hline Tianjin & 0.634 & Hunan & 0.664 \\
\hline Hebei & 0.671 & Guangdong & 0.715 \\
\hline Shanxi & 0.638 & Guangxi & 0.661 \\
\hline Neimenggu & 0.661 & Hainan & 0.630 \\
\hline Liaoning & 0.694 & Chongqing & 0.670 \\
\hline Jilin & 0.694 & Sichuan & 0.701 \\
\hline Heilongjiang & 0.691 & Guizhou & 0.678 \\
\hline Shanghai & 0.620 & Yunnan & 0.678 \\
\hline Jiangsu & 0.671 & Xizang & 0.655 \\
\hline Zhejiang & 0.659 & Shaanxi & 0.663 \\
\hline Anhui & 0.616 & Gansu & 0.686 \\
\hline Fujian & 0.654 & Qinghai & 0.673 \\
\hline Jiangxi & 0.648 & Ningxia & 0.658 \\
\hline Shandong & 0.669 & Xinjiang & 0.679 \\
\hline Henan & 0.661 & & \\
\hline
\end{tabular}

\section{Conclusion}

The paper uses a DEA-SBM model to calculate the efficiency of technological progress. The results of the DEA-SBM show that Shanghai, Guangdong, Jiangsu, Neimenggu, Tianjin, Shandong, Beijing, Zhejiang, Hebei and Hunan have the top 10 highest levels on average from 2009 to 2014 in China. Particularly, we can see that most of these provinces are from the eastern region of China. The reason for this, as mentioned before, is that the economic level of the eastern region is higher than that of other regions. Therefore, the eastern region has more research funds to improve the efficiency of technological progress. Then we can see Jilin, Heilongjiang, Beijing, Tianjin, Liaoning, Hunan, Sichuan, Yunnan, Guangxi and Anhui are the top 10 regarding growth rate from 2009 to 2014 in China. Most of these provinces are from the central region and western region in China. The reason is that although the economic levels of the central region and western region are relatively lower than the eastern region, the rate of economic growth is higher than the eastern region. Figure 4 illustrates the efficiency of technological progress of four regions from 2009 to 2014 in China. As can be seen from the figure, the efficiency of technological progress in the eastern region is significantly higher than that of other regions in China. The main reason given for this is that the economic level of eastern region is higher than that of northeast region, central region and western region. Then an OLS model was used to estimate the relationship of the efficiency of technological progress and network size. The results of the OLS show that network size can promote technological progress. Furthermore, the efficiency of structural holes were calculated. The results show that the top 10 highest in efficiency are Guangdong, Sichuan, Liaoning, Jilin, Heilongjiang, Gansu, Xinjiang, Guizhou and Yunnan. Particularly, most of these provinces are from the northeastern and western regions. Moreover, according to the efficiency, the paper locates the center province of each region. The center provinces of the eastern region are Guangdong, Jiangsu and Hebei. As the efficiency of each province is very close, there are not clear central provinces for the northeastern region. The center province of central region is Hunan. The center provinces of the western region are Sichuan, Gansu, Xinjiang, Guizhou and Yunnan. 


\section{References}

[1] D. Biswas, "Economics of information in the Web economy: Towards a new theory?", Journal of Business Research, vol. 57, no. 7, (2004), pp. 724-733.

[2] J. Frishammar and S. Å. Hörte, "Managing External Information in Manufacturing Firms: The Impact on Innovation Performance*", Journal of Product Innovation Management, vol. 22, no. 3, (2005), pp. 251-266.

[3] B. I. Ke-Xin, M. A. Hui-Zi and P. Huang, "Research on Influencing Factors on the Interactive Relationship between Informatization and Process Innovation", China Soft Science, (2012).

[4] S. Ping and X.-F. Han, "The Convergence Analysis of Total Factor Productivity in China's R\&D Innovation", Finance \& Economics, (2011).

[5] Y.-P. Fang, X. Man and Z. Lin, "A spatial econometric analysis of impact of ICT on service innovation: Based on analysis of 21 cities in Guangdong Province", ActaGeographicaSinica, vol. 68, no. 8, (2013), pp. 1119-1130.

[6] A. Charnes, W. W. Cooper and E. Rhodes, "Measuring the efficiency of decision making units", European Journal of Operational Research, vol. 2, no. 6, (1978), pp. 429-444.

[7] K. Tone, "A slacks-based measure of efficiency in data envelopment analysis", European Journal of Operational Research, vol. 130, no. 3, (2001), pp. 498-509.

[8] J. M. Wooldridge, "Introductory econometrics: a modern approach", Thomson/South-Western, (2006).

[9] R. S. Burt, "Structural Holes: the Social Structure of Competition", Harvard University Press, Cambridge, (1992).

[10] J. Wang, Z. Qin and Z. Chi, "Industrial Chain Integration, Structure Hole and Firm Growth: BYD and Tencent Inc as Examples", Science of Science and Management of S. \& T., vol. 34, no. 11, (2013), pp. 103-115.

[11] Y. Y. Guo, R. Y. Chi and D. Shan. "S\&T intermediary function,network position and performance of industry cluster: evidence from typical industry clusters in Zhejiang Province", Studies in Science of Science, vol. 32, no. 6, (2014), pp. 841-851.

[12] Y.-S. Chen, "Director's 'Structural Hole' Position and Firm's Policy Efficiency", Accounting Research, no. 6, (2015), pp. 48-55. 